\title{
Orofaciodigital syndrome type 11
}

INSERM

\section{Source}

INSERM. (1999). Orphanet: an online rare disease and orphan drug data base.

Orofaciodigital syndrome type 11. ORPHA:141000

Orofaciodigital syndrome type 11 is an extremely rare, sporadic form of Orofaciodigital syndrome (OFDS; see this term) with only a few reported cases, and characterized by facial (blepharophimosis, bulbous nasal tip, broad nasal bridge, downslanting palpebral fissures and low set ears) and skeletal (post-axial polydactyly and fusion of vertebrae) malformations along with severe intellectual disability, deafness and congenital heart defects. 